\title{
Factors determining anti-malarial drug use in a peri-urban population from malaria holoendemic region of western kenya
}

\author{
Carren A Watsierah', Walter GZO Jura², Henry Oyugi ${ }^{1}$, Benard Abong'o ${ }^{1}$, Collins Ouma ${ }^{3,4^{*}}$
}

\begin{abstract}
Background: Interventions to reverse trends in malaria-related morbidity and mortality in Kenya focus on preventive strategies and drug efficacy. However, the pattern of use of anti-malarials in malaria-endemic populations, such as in western Kenya, is still poorly understood. It is critical to understand the patterns of antimalarial drug use to ascertain that the currently applied new combination therapy to malaria treatment, will achieve sustained cure rates and protection against parasite resistance. Therefore, this cross-sectional study was designed to determine the patterns of use of anti-malarial drugs in households $(n=397)$ in peri-urban location of Manyatta-B sub-location in Kisumu in western Kenya.

Methods: Household factors, associated with the pattern of anti-malarials use, were evaluated. Using clusters, questionnaire was administered to a particular household member who had the most recent malaria episode (within $<2$ weeks) and used an anti-malarial for cure. Mothers/caretakers provided information for children aged $<13$ years.

Results: Stratification of the type of anti-malarial drugs taken revealed that $37.0 \%$ used sulphadoxine/ pyrimethamine (SP), 32.0\% artemisinin-based combined therapy (ACT), 11.1\% anti-pyretics, 7.3\% chloroquine (CQ), $7.1 \%$ quinine, 2.5\% amodiaquine (AQ), while $3.0 \%$ used others which were perceived as anti-malarials (cough syrups and antibiotics). In a regression model, it was demonstrated that age $(P=0.050)$, household size $(P=0.047)$, household head $(P=0.049$ ), household source of income $(P=0.015)$, monthly income $(P=0.020)$, duration of use $(P=0.029)$, dosage of drugs taken $(P=0.036)$, and source of drugs $(P=0.005)$ significantly influenced anti-malarial drug use. Overall, $38.8 \%$ of respondents used drugs as recommended by the Ministry of Health.

Conclusion: This study demonstrates that consumers require access to correct and comprehensible information associated with use of drugs, including self-prescription. There is potential need by the Kenyan government to improve malaria care and decrease malaria-related morbidity and mortality by increasing drug affordability, ensuring that the recommended anti-malarial drugs are easily available in all government approved drug outlets and educates the local shopkeepers on the symptoms and appropriate treatment of malaria. Following a switch to ACT in national drug policy, education on awareness and behaviour change is recommended, since the efficacy of ACT alone is not sufficient to reduce morbidity and mortality due to malaria.
\end{abstract}

\section{Background}

There has been some level of improper use of antimalarial drugs despite the fact that Plasmodium falciparum malaria still remains the primary cause of morbidity and mortality amongst millions of people living in

\footnotetext{
* Correspondence: collinouma@yahoo.com

${ }^{3}$ Department of Biomedical Sciences and Technology, Maseno University,

Private Bag, Maseno, Kenya

Full list of author information is available at the end of the article
}

Africa [1]. The lack of proper drug use has been promoted largely over the years by the self-administration of the most common anti-malarial drugs, particularly chloroquine (CQ) [1]. In many situations, practices that could best be described as misuse of drugs have become routine, and in some cases, promoted institutionally [1]. This has further culminated into little interventions to improve the use of anti-malarial drugs. Previously, both $\mathrm{CQ}$ and sulphadoxine/pyrimethamine (SP) were 
perceived to be inexpensive, making it more cost-effective to treat presumptive conditions of malaria rather than to attempt to get microscopic confirmation, especially when this conventional method is unavailable, as commonly experienced in most parts of Africa [1].

In particular, the pattern of anti-malarial drug use in endemic areas of Africa is quite different from the pattern of use of other drugs due to the high intensity of malaria transmission in these areas. In areas of intense malaria transmission, anti-malarial drugs are given repeatedly to treat frequent fevers (even in the absence of malaria) [2]. The practice of self-medication is also increasingly becoming a major health concern. Research finding shows that many illnesses including malaria, are treated without consultations from health professionals [3]. In areas where malaria transmission is endemic, about $50-80 \%$ of people first visit private drug outlets for malaria treatment and use these anti-malarial drugs even without prescription, a practice which has resulted in patterns such as over-use, under-use and irregular use of these drugs [4].

Mortality in approximately 26,000 children and about a third of out-patient attendance in health facilities throughout Kenya annually is attributed to $P$. falciparum malaria. Adult disability due to malaria in this region translates to an economic loss of about 160 million working days per year [5]. The Kenyan National Drug Policy was established in 1994 to check on medication, prescription and promotion of rational drug use. However, the policy has never been meaningfully implemented [5]. It is, therefore, critical to effectively evaluate information on the drug use among the different population. Further dissemination of these facts to both the health authorities and the scientific communities will facilitate effective understanding and help to address the drug use patterns. The current study site, a peri-urban location within Kisumu, is situated in a P. falciparum holoendemic transmission area of western Kenya. Malaria in this region accounts for $40 \%$ of out-patient visits, and $40 \%$ of hospital in-patient admissions [6]. Malaria transmission occurs all year round, peaking in the rainy season months of April and May [7]. Most malaria cases in this region are managed at household level. The patterns of use of anti-malarials include selfprescription, sharing of drugs with friends and relatives and premature discontinuation of treatment course [4]. Anti-malarials are usually bought from commercial pharmacists, retail shops (e.g. grocery, general stores, and community pharmacies) or from licensed and unlicensed drug sellers. Most patients reporting at the health facilities would have at least gone through homebased treatment or local drug shops initially. Thus, seeking health care from practitioners may be due mainly to resistant, severe, or recurrent episodes [4]. Hence, there is concern that household and communities' patterns of use of anti-malarial drugs are often inadequate and inappropriate depending on the practices adopted for use of medicines not only for malaria [8]. The situation may be worse among households living in malaria endemic regions such as western Kenya, since high endemicity may mean that the population invents mechanisms for surviving constant malarial episodes rather than seek adequate healthcare. It is therefore imperative to understand how anti-malarial drugs are used in such areas. In addition, since few documented studies have been carried out to link household factors such as economic level coupled with high endemicity, with the patterns of use of anti-malarials, it is upon this background that we report on the factors determining the patterns of antimalarial drugs use among the residents of a peri-urban region of Kisumu in Western Kenya.

\section{Methods}

\section{Study setting}

The current study was carried out in Manyatta-B sublocation in Winam division of Kisumu. The area consists of three villages, Lower Kanyakwar, Upper Kanyakwar and Kuoyo, which are further divided into nine smaller units depending on the sub-clan boundaries. Within the sub-clan boundaries are informal dwellings within and outside some of the homesteads. According to the last population census, the total number of inhabitants in this sub-location is 21,027 in 6,035 households [9]. The total area is $3.3 \mathrm{~km}^{2}$ with a density of 6,372 people $/ \mathrm{km}^{2}$ [9]. Housings consist of mostly rented rooms within an area of $10-20 \mathrm{~m}^{2}$ for 4-8 persons in a household. These individuals live in a congested and miserable conditions, with considerable lack of the basic necessities of life, such as clean piped-water and proper housing conditions [10]. The density of the population and the closely-packed housing conditions contributes to poor drainage; hence, stagnant water, which form good breeding grounds all year round for malaria vectors [11].

\section{Study participants}

In order to determine the patterns of use of anti-malarial drugs in the study population at a point in time, residents living within households $(n=397)$ in the above described peri-urban region of Kisumu in western Kenya, were recruited. This was a descriptive cross-sectional survey in which sampling was carried out using cluster method as previously described [12]. A total of 6,035 households in nine clusters were sampled in order to achieve the required sample size. Data was collected through interviews, using structured questions in selected households in which diagnosed or self-reported episodes of malaria occurred within the last two weeks prior to the interview dates. 
Included in the study were individuals living in the above described households and who had experienced malaria and used anti-malarial or other drugs perceived by them as anti-malarial, due to self/presumptive or laboratory diagnosis within the previous two weeks. In the absence of laboratory diagnosis, malaria according to residents in the study area was defined by either the presence or mixed symptoms of fever, diarrhoea, vomiting and pain in the joints. However, if more than one individual in a household had experienced malaria and had used anti-malarial or other drugs viewed or perceived by them as an anti-malarial within the described period (i.e. two weeks), then focus was on the most current episode, while the rest were excluded. This strategy was adopted so as to capture the most recent pattern of anti-malarial drug use and to minimize errors associated with recall. If no one had experienced malaria episodes within the previous two weeks, the interviewer moved to the next household in the cluster. Correct drug use was assessed by questionnaires through identification of the drug used and whether or not the respondents used it as per the prescription. The study was approved by the ethical and scientific review committees at the Kenya Medical Research Institute and the Great Lakes University of Kisumu Ethical Review Board (GERB), Kenya.

\section{Sampling design}

This study employed cluster sampling method in selecting the households in the study area. A total of nine clan regions were chosen as clusters. The study units comprised households within the cluster that had its member experiencing malaria in the last two weeks. The probability of selection of the primary sampling units for each cluster was proportional to the estimated sample size. From each cluster, households were then selected on continuous basis until the total number $(\mathrm{n}=$ 397) required was achieved.

\section{Research procedure}

The quantitative data, which was collected from 397 households was performed through interviews using structured questions. The tool of data collection was a pre-prepared questionnaire, which was administered to the particular household member, who had previous malaria episode and used anti-malarial or drug perceived to be an anti-malarial. However, in cases of children below the age of 13 years, mothers or caretakers provided the information. Using clusters, households with malaria episodes were established first through identification interview, which involved all the households starting with exactly the first household visited in the cluster. The interview was then repeated in all the households identified until the required number was achieved. As stated above, particular emphasis was on the most recent episode of self/presumptive or laboratory diagnosed malaria in the household. Research/field assistants $(n=5)$ who were involved in data collection, used drug charts containing samples of commonly used anti-malarial drugs to aid in recall and to validate reports. In addition, remaining packages or tablets were reviewed where possible.

Prior to the actual study, the field assistants' who were themselves residents of the study sub-location and with a minimum of form four level of education, were interviewed and recruited as enumerators. They were required to be fluent in English, Swahili and DhoLuo languages. Training of the research assistants on survey interviewing techniques was carried out for one day followed by a second day of pre-testing of survey tools and methodologies in a neighbouring community with the same characteristics. Based on the experiences and results of the pre-test, further re-training and refining of techniques of interviewing and modification of research tool was performed.

\section{Statistical analyses}

Statistical analyses were performed using SPSS (Version 15.0). Logistic regression analysis between the independent and dependant variables was used to identify variables associated with pattern of use of anti-malarial drugs. The variables included in the logistic regression model included; demographic (age, gender, marital status, household head, and household size); socio-economic (household breadwinner, source of income, household monthly income, education level and ability to read) and environmental (source of drugs, distance to source of drugs, and availability of anti-malarial drug at source) factors. The variables that were significantly associated with pattern of use (drugs taken, duration, dosage and source of drugs) were further analyzed using Chisquare tests. Proportions on knowledge, drug-taking behaviour and correctness of patterns of use were determined. A $P \leq 0.05$ was considered statistically significant.

\section{Results}

Demographic characteristics of the study participants

A total of 397 households were included in the analyses to determine factors associated with anti-malarial drugs use patterns. Overall, males were 183 (46.1\%) while females were $214(53.9 \%)$ (Table 1$)$. In terms of age, those who were aged $<13$ years were 262 (66.0\%) while $135(34.0 \%)$ were $\geq 13$ years. The distribution of individuals per household were as follows; $1-2$ individuals [81 (20.4\%)], 3-5 individuals [215 (52.4\%)], and $\geq 6$ individuals [101 (25.4\%)]. Households headed by husbands were $267(67.3 \%)$; wives $76(19.1 \%)$ and caretakers 51 $(12.8 \%)$, while $3(0.8 \%)$ were headed by others. 
Table 1 Demographic characteristics and the use of three major anti-malarial drugs

\begin{tabular}{|c|c|c|c|c|c|c|c|c|}
\hline \multirow[t]{2}{*}{ Demographic factors } & \multicolumn{4}{|c|}{ Drugs taken } & \multicolumn{2}{|c|}{ Duration of use } & \multicolumn{2}{|c|}{ Dosage of use } \\
\hline & & $S P$ & $A C T$ & Quinine & Correct & Incorrect & Correct & Incorrect \\
\hline \multirow[t]{2}{*}{ Age } & $<13$ years & 98 (37.4\%) & $86(32.8 \%)$ & $20(7.6 \%)$ & $159(60.7 \%)$ & 103 (39.3\%) & $202(77.1 \%)$ & $60(22.9 \%)$ \\
\hline & $\geq 13$ years & $49(36.3 \%)$ & 41 (30.4\%) & $8(5.9 \%)$ & $69(51.1 \%)$ & $51(48.9 \%)$ & $102(75.6 \%)$ & $33(24.4 \%)$ \\
\hline \multirow[t]{2}{*}{ Gender } & Male & $67(36.6 \%)$ & $60(32.8)$ & $16(8.7 \%)$ & $104(56.8 \%)$ & $79(43.2 \%)$ & $146(79.8 \%)$ & 37 (20.2\%) \\
\hline & Female & $80(37.4 \%)$ & 67 (31.3\%) & $12(5.6 \%)$ & $124(57.9 \%)$ & $90(42.1 \%)$ & $158(73.8 \%)$ & $56(26.2 \%)$ \\
\hline \multirow[t]{5}{*}{ Marital status } & Single & 7 (30.4\%) & $6(26.1 \%)$ & $2(8.7 \%)$ & $14(60.9 \%)$ & 9 (39.1\%) & $18(78.3 \%)$ & $5(21.7 \%)$ \\
\hline & Married & $31(31.2 \%)$ & 31 (35.2\%) & $3(3.4 \%)$ & $50(56.8 \%)$ & $38(43.2 \%)$ & $67(76.1 \%)$ & $21(23.9 \%)$ \\
\hline & Separated & $1(50.0 \%)$ & 0 & 0 & $0(0.00 \%)$ & $2(100 \%)$ & $1(50.0 \%)$ & $1(50.0 \%)$ \\
\hline & Widowed & $5(41.7 \%)$ & 0 & $3(25.0 \%)$ & $8(66.7 \%)$ & $4(33.3 \%)$ & $8(66.7 \%)$ & $4(33.3 \%)$ \\
\hline & Underage & $102(37.6 \%)$ & 90 (33.2\%) & $20(7.4 \%)$ & $155(57.3 \%)$ & $116(42.8 \%)$ & $209(77.1 \%)$ & $62(22.9 \%)$ \\
\hline \multirow[t]{4}{*}{$\mathrm{HH}$ head } & Husband & $108(40.4 \%)$ & 88 (33.0\%) & 13(4.9\%) & $161(60.3 \%)$ & 106 (39.7\%) & $205(76.8 \%)$ & $62(23.2 \%)$ \\
\hline & Wife & $24(31.6 \%)$ & 25 (32.9\%) & 9 (11.8\%) & 35 (46.1\%) & 41 (53.9\%) & 58 (76.3\%) & $18(23.7 \%)$ \\
\hline & Caretaker & $14(27.5 \%)$ & 13 (25.5\%) & $6(11.8 \%)$ & 30 (58.8\%) & $21(41.2 \%)$ & 39 (76.5\%) & 12 (23.5\%) \\
\hline & Others & 1 (33.3\%) & 1 (33.3\%) & 0 & 1 (33.3\%) & 2 (66.7\%) & 2 (66.7\%) & 1 (33.3\%) \\
\hline \multirow[t]{3}{*}{ HH size } & $1-2$ & $32(39.5 \%)$ & 27 (33.3\%) & $4(4.9 \%)$ & 42 (51.9\%) & $39(48.1 \%)$ & 59 (72.8\%) & $22(27.2 \%)$ \\
\hline & $3-5$ & 83 (38.6\%) & 65 (30.2\%) & $16(7.4 \%)$ & 127 (59.1\%) & 88 (40.9\%) & 167 (77.7\%) & $48(22.3 \%)$ \\
\hline & 6 and above & 32 (31.7\%) & 35 (34.7\%) & 8 (7.9\%) & 59 (58.4\%) & 42 (41.6\%) & 78 (77.2\%) & $23(22.8 \%)$ \\
\hline
\end{tabular}

$\mathrm{HH}$ - Household, SP-Sulphadoxine pyremethamine, ACT- Artemether-based combined therapies. Proportionality determined by Chi-square test. From the Table, most respondents used SP and ACT relative to other drugs, with close variations in their use. In addition, more than half of the respondents took the drugs within the correct duration in each case considered, except for households who were headed by wives (46.1\%). Furthermore, majority in the different categories used the correct dose as opposed to lower proportions of individuals who used the incorrect dose.

Respondents who were married were 88 (22.8\%); single $23(5.8 \%)$ and widowed $12(3.0 \%)$ while underage individuals (i.e. below 15 years and not marriageable) were 271 (68.4\%).

Levels of education varied in that approximately $13.4 \%$ had achieved primary education, $12.1 \%$ secondary education, $2.5 \%$ had post-secondary education, while $14.1 \%$ were still in school. In addition, 3.0\% did not have any form of education while $54.9 \%$ were underage children (i.e. $<6$ years and not started any formal education). The primary breadwinners for most households were husbands (69.9\%), wives (15.9\%) and others (14.2\%). Selfemployment (37.9\%) was the main source of income while petty business $(25.5 \%)$, salary $(20.2 \%)$, casual work (15.4\%), and farming and the other sources of income were $(1 \%)$. The respondents with monthly income of below KShs. 4,500 were 41.2\%, between KShs. 4,5009,000 were $46.5 \%$, while over KShs. 9,000 were $12.4 \%$. A total of $79.8 \%$ and $20.2 \%$ of respondents were able and unable to read prescriptions, respectively (Table 1 ).

In terms of drug use, further findings revealed that most respondents used SP and ACT relative to other drugs, with close variations in their use. In addition, more than half of the respondents took the drugs within the correct duration in each case considered, except for households who were headed by wives (46.1\%). Furthermore, majority in the different categories used the correct dose as opposed to lower proportions of individuals who used the incorrect dose (Table 1).

\section{Sources of anti-malarials in the peri-urban population}

In order to determine whether the drugs were acquired from the correct sources with the right prescriptions, respondents were asked about the sources of their drugs. Results indicated that a total of $30.5 \%$ of drugs were from government institutions, $30.3 \%$ from nearby shops, $18.3 \%$ from pharmacies/chemists, $16.4 \%$ from private clinics, $1.0 \%$ from street vendors, $1.5 \%$ from friends/neighbours/relatives, and $2.0 \%$ were left-over drugs in the households.

Since the source can determine the type of drug used, the study further assessed the pattern of individual drug used from the above sources. For quinine, the main source was government health institutions (66.4\%) and private clinics (33.6\%). The ACT drugs were mainly sourced from government health institutions (60.0\%), pharmacy/chemists (25.2\%) and private clinics (14.8\%). The main source of SP drugs was shops/kiosks (70\%) while pharmacy/chemists $(21.2 \%)$ and private clinics (8.8\%). Other sources of anti-malarials included street vendors, friends/relatives/neighbours and left-over medicine in the households whose proportions were $<20 \%$ for each of the categories.

Distance to the source of an anti-malarial drug was measured by the time taken to reach the source while walking. Respondents who took less than 30 minutes were $57.4 \%$ while $42.6 \%$ took more than 30 minutes to reach the source of drug. Furthermore, $48.0 \%$ of respondents accessed the anti-malarial drugs at the respective 
places/sources because those were the types of drugs that were available and the source was a shorter distance to the respondent (Table 2).

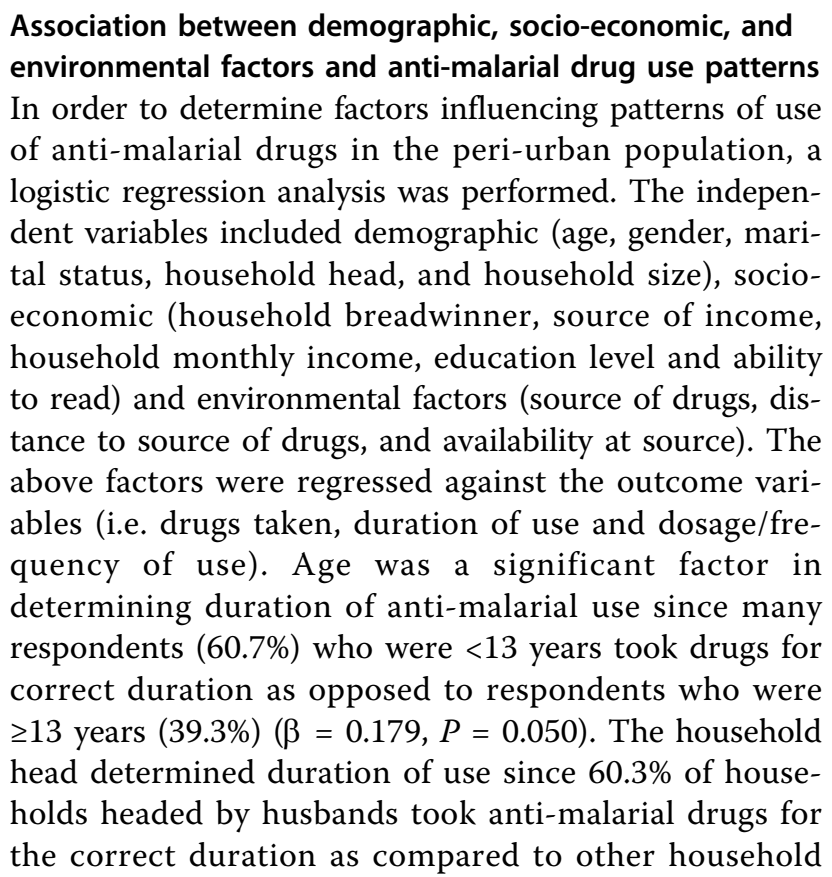

headed by either wives or any other person other than husbands $(\beta=0.093, P=0.047 \%)$. In addition, household size significantly influenced the types of anti-malarial drugs used ( $\beta=0.092, P=0.049)$ (Table 3). A higher proportion of the respondents whose household sizes were $3-5(68.9 \%)$ or $\geq 6(20.1 \%)$ used SP as compared to households with $1-2$ individuals $(11.0 \%)(P=0.015)$. Furthermore, household source of income significantly influenced duration for use $(\beta=0.097, P=0.050)$ since a higher proportion of respondents who were salaried $(21.9 \%)$ or self-employed $(38.6 \%)$ used drugs within the specified duration relative to those with other sources of income $(P=0.017)$. In addition, household monthly income significantly influenced dosage of the drugs used $(\beta=0.113, P=0.034$ ) (Table 3$)$, primarily due to the fact that higher proportions of respondents with an income salary of KShs. 4500-9000 (48.5\%) took the correct dosage of drugs as opposed to individuals with other incomes $(P=0.020)$.

Additional analyses revealed that the source of drugs significantly predicted pattern of anti-malarial drug use by determining dosage $(\beta=0.013, P=0.005)$ and drug taken $(\beta=0.113, P=0.036)$. This observation is in line with the fact that higher proportions of respondents who took the correct dosage of drug either acquired

Table 2 Socio-economic factors and the use of three major anti-malarial drugs

\begin{tabular}{|c|c|c|c|c|c|c|c|c|}
\hline \multirow[t]{2}{*}{ Socio-economic factors } & \multicolumn{4}{|c|}{ Drugs taken } & \multicolumn{2}{|c|}{ Duration of use } & \multicolumn{2}{|c|}{ Dosage of use } \\
\hline & & $S P$ & $A C T$ & Quinine & Correct & Incorrect & Correct & Incorrect \\
\hline \multirow[t]{6}{*}{ Education level } & Primary & $19(35.8 \%)$ & $18(34.0 \%)$ & $5(9.4 \%)$ & $28(52.8 \%)$ & $25(47.2 \%)$ & $44(83.0 \%)$ & $9(17.0 \%)$ \\
\hline & Secondary & $19(39.6 \%)$ & $15(31.3 \%)$ & $1(2.1 \%)$ & $5(50.0 \%)$ & $21(43.8 \%)$ & $36(75.0 \%)$ & $12(25.0 \%)$ \\
\hline & Post-Secondary & $5(50.0 \%)$ & $3(30.0 \%)$ & 0 & $27(56.3 \%)$ & $5(50.0 \%)$ & $6(60 \%)$ & $4(40.0 \%)$ \\
\hline & Still in school & 17 (30.4\%) & $20(35.7 \%)$ & $4(7.1 \%)$ & $37(66.1 \%)$ & 19 (33.9\%) & $45(80.4 \%)$ & $11(19.6 \%)$ \\
\hline & None & $4(33.3 \%)$ & 0 & $1(8.3 \%)$ & $10(83.3 \%)$ & $2(16.7 \%)$ & $8(66.7 \%)$ & $4(33.3 \%)$ \\
\hline & Under 6 & $83(38.1 \%)$ & $71(32.6 \%)$ & $17(7.8 \%)$ & $121(55.5 \%)$ & $97(44.5 \%)$ & $165(75.7 \%)$ & $53(24.3 \%)$ \\
\hline \multirow[t]{3}{*}{$\mathrm{HH}$ breadwinner } & Husband & 105 (37.9\%) & $97(35.0 \%)$ & $16(5.8 \%)$ & 164 (59.2\%) & 113 (40.8\%) & 219 (79.1\%) & $58(20.9 \%)$ \\
\hline & Wife & $21(33.3 \%)$ & $18(28.6 \%)$ & $4(6.3 \%)$ & $30(47.6 \%)$ & $33(52.4 \%)$ & $45(71.4 \%)$ & $18(28.6 \%)$ \\
\hline & Others & $21(37.3 \%)$ & $11(20.4 \%)$ & $8(14.8 \%)$ & $34(61.1 \%)$ & $22(38.9 \%)$ & $39(68.5 \%)$ & 17 (31.5\%) \\
\hline \multirow[t]{6}{*}{$\mathrm{HH}$ inc. source } & Salaried & 27 (33.8\%) & $29(36.3 \%)$ & $6(7.5 \%)$ & $50(62.5 \%)$ & $30(37.5 \%)$ & $65(81.3 \%)$ & $15(18.8 \%)$ \\
\hline & Self employed & $53(35.3 \%)$ & 47 (31.3\%) & $7(4.7 \%)$ & $96(64.0 \%)$ & $54(36.0 \%)$ & $110(73.3 \%)$ & $40(26.7 \%)$ \\
\hline & Petty business & $42(41.6 \%)$ & $27(26.7 \%)$ & 11 (10.9\%) & $51(50.5 \%)$ & $50(49.5 \%)$ & $79(78.2 \%)$ & $22(21.8 \%)$ \\
\hline & Casual worker & $24(39.3 \%)$ & $23(37.7 \%)$ & $4(6.6 \%)$ & $29(47.5 \%)$ & $32(52.5 \%)$ & $47(77.0 \%)$ & $14(23.0 \%)$ \\
\hline & Farming & $1(50.0 \%)$ & $1(50.0 \%)$ & 0 & $1(50.0 \%)$ & $1(50.0 \%)$ & $1(50.0 \%)$ & $1(50.0 \%)$ \\
\hline & Others & 0 & 0 & 0 & $1(50.0 \%)$ & $1(50.0 \%)$ & $1(50.0 \%)$ & $1(50.0 \%)$ \\
\hline \multirow[t]{3}{*}{$\mathrm{HH}$ monthly inc. } & Below Ksh.4500 & $56(34.4 \%)$ & $48(29.4 \%)$ & $11(6.7 \%)$ & $85(52.1 \%)$ & 78 (47.9\%) & 115 (70.6\%) & $48(29.4 \%)$ \\
\hline & Ksh.4500-9000 & $74(40.2 \%)$ & $58(31.5 \%)$ & $12(6.5 \%)$ & 111 (60.3\%) & 73(39.7\%) & 147 (79.9\%) & 37 (20.1\%) \\
\hline & Over Ksh. 9000 & 17 (35.4\%) & $21(43.8 \%)$ & $4(8.3 \%)$ & $30(62.5 \%)$ & 18 (37.5\%) & $40(83.3 \%)$ & $8(16.7 \%)$ \\
\hline \multirow[t]{2}{*}{ Ability to read } & Able to read & 121 (38.2\%) & $114(36.0 \%)$ & $20(6.3 \%)$ & 181 (57.1\%) & 136 (42.9\%) & $246(77.6 \%)$ & $71(22.4 \%)$ \\
\hline & Unable to read & 26 (32.9\%) & $13(16.5 \%)$ & 7 (8.9\%) & 46 (58.2\%) & 33 (41.8\%) & 57 (72.2\%) & $22(27.8 \%)$ \\
\hline
\end{tabular}

Data are presented as proportions ( $\mathrm{n}, \%)$. HH-Household, SP- Sulfadoxine pyremethamine, ACT- Artemether-based combined therapies, inc.-Income. From the results above the drugs that were taken by majority of the respondents were SP and ACT in all the socio-economic factors considered, with very small differences in proportions in each category. In addition, averagely half of the households had used drugs for correct duration, unlike households whose breadwinners were wives (47.6\%) and those who depended on casual work as the main source of income (47.5\%). Moreover, most households took correct dosages of drugs with majority scoring more than $70 \%$ in each socio-economic factor considered. 
Table 3 Demographic, socio-economic and environmental factors associated with patterns of use of anti-malarial drugs

\begin{tabular}{lccc}
\hline & & Dependent variables & \\
\cline { 2 - 4 } & Drugs taken & Dosage of use & Duration of use \\
\hline Independent variables & & & \\
\hline Age (A) & $\beta=0.113, P=0.230$ & $\beta=0.006, P=0.949$ & $\beta=0.179, \boldsymbol{P}=\mathbf{0 . 0 5 0}$ \\
Gender (G) & $\beta=0.008, P=0.872$ & $\beta=0.061, P=0.235$ & $\beta=0.018, P=0.722$ \\
Marital status (MS) & $\beta=0.101, P=0.341$ & $\beta=0.115, P=0.279$ & $\beta=0.105, P=0.322$ \\
Household size (HHS) & $\beta=0.092, P=0.049$ & $\beta=0.027, P=0.606$ & $\beta=0.008, P=0.873$ \\
Household head (HHH) & $\beta=0.019, P=0.726$ & $\beta=0.011, P=0.841$ & $\beta=0.093, \boldsymbol{P}=\mathbf{0 . 0 4 7}$ \\
Education level (EL) & $\beta=0.018, P=0.828$ & $\beta=0.132, P=0.104$ & $\beta=0.057, P=0.486$ \\
Household breadwinner (HHB) & $\beta=0.008, P=0.883$ & $\beta=0.086, P=0.113$ & $\beta=0.071, P=0.188$ \\
Household income source (HIS) & $\beta=0.028, P=0.597$ & $\beta=0.010, P=0.846$ & $\beta=0.097, \boldsymbol{P}=\mathbf{0 . 0 5 0}$ \\
Household monthly income (HHI) & $\beta=0.037, P=0.486$ & $\beta=0.113, \boldsymbol{P}=\mathbf{0 . 0 3 4}$ & $\beta=0.064, P=0.233$ \\
Ability to read (AR) & $\beta=0.059, P=0.268$ & $\beta=0.005, P=0.926$ & $\beta=0.030, P=0.570$ \\
Source of drug (SD) & $\beta=0.113, P=0.036$ & $\beta=0.013, \boldsymbol{P}=\mathbf{0 . 0 0 5}$ & $\beta=0.029, P=0.596$ \\
Distance to source (DS) & $\beta=0.049, P=0.373$ & $\beta=0.021, P=698$ & $\beta=0.058, P=0.293$ \\
Availability at source (AS) & $\beta=0.092, P=0.046$ & $\beta=0.002, P=965$ & $\beta=0.060, P=0.252$ \\
\hline
\end{tabular}

Logistic regression analysis between the independent and dependant variables was used to identify variables associated with pattern of use of anti-malarial drugs, including demographic, socio-economic and environmental factors. $P$-values in bold were statistically significant at $P \leq 0.05$. $b=$ standard co-efficient. The result above shows that age, household size, source of drugs and availability of drugs at the source work together to influence types of anti-malarial that are taken in the households. Furthermore, household monthly income and source of drug work together to influence dosage of use; while age, household head and household income source work together to influence duration of use of these drugs.

their drugs at government institutions $(29.3 \%)$ or pharmacy/chemists $(24 \%)$ relative to other sources $(P=$ $0.004)$. Moreover, availability at source significantly influenced anti-malarial drug taken $(\beta=0.092, P=$ 0.046) (Table 3). Taken together, these results demonstrate that in this peri-urban population of Kisumu, age, household head, household size, source of income, level of monthly income, the source of anti-malarial and availability at the source significantly influence pattern of anti-malarial use.

\section{Discussion}

The importance of understanding how anti-malarial drugs are used in a community and consequently how their use might be improved draws a considerable interest and concern in translating anti-malarial efficacy into effectiveness in various settings in malaria-affected communities. This study was designed to investigate the demographic, socio-economic and environmental factors that influence anti-malarial drug use in a peri-urban region within Kisumu in western Kenya. The findings presented here demonstrate that age, household head, household size, source of income, level of monthly income, the source of anti-malarial and availability at the source significantly influence pattern of anti-malarial use.

Age influenced pattern of anti-malarial use by influencing duration for use. A total of $60.7 \%$ individuals $<13$ years used drugs for correct duration while only $51.1 \%$ $\geq 13$ years of age used drugs for correct duration. Higher proportion of individuals (i.e. children) $<13$ years taking drugs for correct duration may be attributed to the fact that they are dependent on caretakers in making health decisions and supervisions. Further analyses demonstrated that gender and marital status did not influence the pattern of anti-malarial use. This finding is consistent with a previous study carried out in Turkey to determine knowledge on malaria and behaviour in endemic rural area in which there were no relationships between adherence and race, gender and marital status [13]. However, the current findings and the previous ones [13] are inconsistent with a study carried out in Sudan among college students on self-medication practices with antibiotics and anti-malarial drugs [14] and in a community-based cross-sectional survey in Tulu District in southern-central Ethiopia [15], in which it was demonstrated that treatment-seeking behavior for malaria was not affected by age.

Household head influenced the pattern of use of antimalarial drugs by influencing the duration for use. This observation could be attributed to the fact that husbands, being majority of the household heads were also the primary breadwinners, and hence, were influencing health decisions in the household. In addition, the household size influenced patterns of use of anti-malarial drugs since it determined the anti-malarial drugs taken in the household. Households with 1-2 individuals had a tendency to take the correct dosage within the correct duration relative to households with three or more individuals, which demonstrated an irregular 
pattern. This could be attributed to the fact that larger household sizes, due to economic strain, need more finances to maintain, hence would prefer cheaper antimalarials, which then affects the type, dosage and duration of use.

Assessment of socio-economic factors that could influence anti-malarial drug use revealed that households with a monthly income of KShs. 9000 took correct dosages as opposed to those with other incomes. Furthermore, most households which depended on salary and on self-employment took drugs for correct duration as opposed to households with other sources of income. These results are comparable to a study in Uganda [16] and Ethiopia [17], which were designed to determine healthcare-seeking behaviour for malaria treatment in which higher income households frequently obtained their drugs from commercial drug stores because they could afford them. In line with this argument, higher income households in the current study were also able to afford the drugs and hence use correct doses.

Assessment of environmental factors that can influence anti-malarial drug use revealed that the source of drugs and availability at source influenced pattern of use by influencing dosage and drugs taken, respectively. This observation was mainly because higher proportions of the respondents who took the correct dosage of drug either acquired the drugs from government health facilities or from pharmacy/chemists as opposed to other sources. In addition, availability of drugs determined which drugs are obtainable for use. These findings are consistent with findings in a study carried out in Southern Ethiopia on self-treatment of malaria in rural communities, where it was demonstrated that anti-malarial drugs were bought from markets or any shops because it was close to home (43.6\%), the drugs were available (25.8\%), the shops were easily accessible $(20.9 \%)$, and waiting time was short (11.5\%) [17]. In a different study in Kenya, it has been demonstrated that utilization of health facilities decreased slightly with increasing distance of participants' place of residence to health facilities for up to $6 \mathrm{~km}$ [18]. In line with these previous observations, findings in this study indicate that large segment of the households in the peri-urban population are living within a short radius from health facilities, or alternative sources of anti-malarial drugs. Consequently, it is reasonable to suggest that this may produce a levelling effect and may not be an influencing factor in pattern of use of anti-malarial. In terms of source of drugs, most respondents in the current study obtained their anti-malarial drugs from government health facilities, contrary to previous studies in other similar P. falciparum endemic regions in which anti-malarial drugs were obtained from local shops $[19,20]$. However, the findings from the current study concurs with the behavioural patterns observed in a study in Kipsamoite area, which is a highland region of Kenya (with unstable malaria transmission pattern) in which medical facilities were the most common initial treatment source for both adults $(66.0 \%)$ and children $(66.7 \%)$. Local shops were the most popular alternative, providing initial treatment for $19.0 \%$ of adults and $30.3 \%$ of children [21]. The observed patterns in the current study could be due to improved availability and provision of subsidized anti-malarial drugs at government facilities. It is important to note that even though local shops were not the most popular source of anti-malaria drugs in the current setting, they were the most frequently sought source after government medical facilities. As a result, a significant portion of the population received anti-malarial drugs for perceived malaria from the local shops. These findings indicate that, despite increased reliance on government facilities in this peri-urban area, local shops are an important source of anti-malarial drugs and should be considered when designing treatment and intervention programmes.

\section{Conclusion}

In conclusion, there is potential need by the Kenyan government to improve malaria care and decrease the malaria-related morbidity and mortality by increasing drug affordability, ensuring that the recommended antimalarial drugs are easily available in all government approved drug outlets and in addition, educate the local shopkeepers on the symptoms and appropriate treatment of malaria. Additional efforts should be made in further organizing awareness campaigns to educate the locals on the clinical symptoms of malaria. Such educational interventions have been shown to change malaria treatment-seeking behaviour in other malaria endemic areas [22-24].

\section{Acknowledgements}

We are indebted to the study participants within the peri-urban region of Kisumu in Western Kenya and the enumerators for data collection. These data are published with the approval of the Great Lakes University of Kisumu and Director, Kenya Medical Research Institute (KEMRI).

Financial support: This work was supported by kind contributions from friends.

\section{Author details}

${ }^{1}$ Great Lakes University of Kisumu, P.O. Box 2224-40100, Kisumu, Kenya. ${ }^{2}$ Department of Zoology, Maseno University, Private Bag, Maseno, Kenya. ${ }^{3}$ Department of Biomedical Sciences and Technology, Maseno University, Private Bag, Maseno, Kenya. ${ }^{4}$ University of New Mexico/Centre for Global Health Research, Kenya Medical Research Institute, P.O. Box 1578-40100, Kisumu, Kenya.

\section{Authors' contributions}

CAW designed, carried out the survey studies in the peri-urban population and participated in the drafting of the manuscript. WGZOJ and CO designed the study and participated in the drafting of the manuscript. $\mathrm{HO}$ and BA 
performed the statistical analysis. All authors read and approved the final manuscript.

\section{Competing interests}

The authors declare that they have no competing interests.

Received: 15 August 2010 Accepted: 26 October 2010

Published: 26 October 2010

\section{References}

1. Bloland PB, Kachur SP, Williams HA: Trends in antimalarial drug deployment in sub-Saharan Africa. J Exp Biol 2003, 206(Pt 21):3761-3769.

2. Marsh VM, Mutemi WM, Muturi J, Haaland A, Watkins WM, Otieno G, Marsh K: Changing home treatment of childhood fevers by training shop keepers in rural Kenya. Trop Med Int Health 1999, 4:383-389.

3. WHO: Report on the progress in Essential Drugs and Management Policy, 1998-1999. 1999.

4. Hamel MJ, Odhacha A, Roberts JM, Deming MS: Malaria control in Bungoma District, Kenya: a survey of home treatment of children with fever, bednet use and attendance at antenatal clinics. Bull World Health Organ 2001, 79:1014-1023.

5. IHRS: Rational Use of Drugs: What it is and what are the prerequisite for its fulfilments? Journal of Health 2006, 10:2-8.

6. WHO: The use of antimalarials. Report of $\mathrm{WHO}$ informal consultations 13-17, November. 2000.

7. Beier JC, Oster CN, Onyango FK, Bales JD, Sherwood JA, Perkins PV, Chumo DK, Koech DV, Whitmire RE, Roberts CR, Diggs CL, Hoffman SL: Plasmodium falciparum incidence relative to entomologic inoculation rates at a site proposed for testing malaria vaccines in western Kenya. Am J Trop Med Hyg 1994, 50:529-536.

8. Buabeng KO, Duwiejua M, Dodoo AN, Matowe LK, Enlund H: Self-reported use of anti-malarial drugs and health facility management of malaria in Ghana. Malar J 2007, 6:85.

9. CBS: Kisumu District Development Plan (KDDP). 2001, 1-11.

10. World Vision Report: 2008.

11. WHO: Conference of Experts on rational use of drugs. Nairobi; 1985

12. Cochran WG: Sampling Techniques. New York: Wiley; 3 1977, 205.

13. Simsek $Z$, Kurcer MA: Malaria: knowledge and behaviour in an endemic rural area of Turkey. Public Health 2005, 119:202-208.

14. Deressa W: Treatment-seeking behaviour for febrile illness in an area of seasonal malaria transmission in rural Ethiopia. Malar J 2007, 6:49.

15. Awad Al, Eltayeb IB: Self-medication practices with antibiotics and antimalarials among Sudanese undergraduate university students. Ann Pharmacother 2007, 41:1249-1255.

16. Tutembe P: Determinants of health care seeking behaviour for malaria treatment in Uganda. 5th MIM Pan-African Malaria Conference (KICC, Nairobi, Kenya, 2-6 November, 2009) 2009, 152-153.

17. Deressa W, Ali A, Enqusellassie F: Self-treatment of malaria in rural communities, Butajira, southern Ethiopia. Bull World Health Organ 2003, 81:261-268.

18. Gething PW, Noor AM, Zurovac D, Atkinson PM, Hay SI, Nixon MS, Snow RW: Empirical modelling of government health service use by children with fevers in Kenya. Acta Trop 2004, 91:227-237.

19. Abuya TO, Mutemi W, Karisa B, Ochola SA, Fegan G, Marsh V: Use of overthe-counter malaria medicines in children and adults in three districts in Kenya: implications for private medicine retailer interventions. Malar J 2007, 6:57.

20. Malik EM, Hanafi K, Ali SH, Ahmed ES, Mohamed KA: Treatment-seeking behaviour for malaria in children under five years of age: implication for home management in rural areas with high seasonal transmission in Sudan. Malar J 2006, 5:60.

21. Sumba PO, Wong SL, Kanzaria HK, Johnson KA, John CC: Malaria treatment-seeking behaviour and recovery from malaria in a highland area of Kenya. Malar J 2008, 7:245.

22. Alvarado BE, Alzate A, Mateus JC, Carvajal R: Effects of an educational and participatory community intervention on malaria control in Buenaventura, Colombia. Biomedica 2006, 26:366-378.

23. Alvarado BE, Gomez E, Serra M, Carvajal R, Carrasquilla G: Evaluation of an educational strategy on malaria in rural areas of the Colombian Pacific Coast. Biomedica 2006, 26:342-352.
24. Tavrow P, Shabahang J, Makama S: Vendor-to-vendor education to improve malaria treatment by private drug outlets in Bungoma District, Kenya. Malar J 2003, 2:10.

doi:10.1186/1475-2875-9-295

Cite this article as: Watsierah et al:: Factors determining anti-malarial drug use in a peri-urban population from malaria holoendemic region of western kenya. Malaria Journal 2010 9:295.

\section{Submit your next manuscript to BioMed Central and take full advantage of:}

- Convenient online submission

- Thorough peer review

- No space constraints or color figure charges

- Immediate publication on acceptance

- Inclusion in PubMed, CAS, Scopus and Google Scholar

- Research which is freely available for redistribution
Ciomed Central 